\title{
Teenage Cigarettes Smoking and the Situation in Saudi Arabia in Terms of Prevalence, Predicting and Preventing Factors, A Narrative Review
}

\author{
Ahmad Y. Alzahrani
}

\begin{abstract}
- teenage smoking is a growing health issue in the Saudi population, and it could be predicted by some factors. To understand teenage smoking risk factors in our population, we reviewed the literature on related topics. A narrative review of the related literature published in the English language from 2008 to 9th July 2019 using PubMed database was performed to know the prevalence of teenage smoking, important predictors and possible preventive measures. The prevalence of adolescent smoking was ranging from 9.2 to $20 \%$. The main predicting factors were male gender, parental smoking, and education status, smoking peers, having pocket money and watching smoking sceneries in movies. The important preventive strategies were improving awareness, excising tax and increasing legal age of smoking to 21 years. Our study revealed that most of the Saudi youth aged from 15-24 years started smoking at an age younger than 18 years which call for the development and implementation of preventive programs to minimize smoking initiation among teenagers.
\end{abstract}

Index Terms — adolescents; cigarette; risks; smoking.

\section{INTRODUCTION}

According to World Health Organization WHO, 5.4 million annual deaths are caused by smoking, and more than $80 \%$ of tobacco-related deaths are expected to be in the low and middle-income countries by 2030 [1]. Tobacco smoking including secondhand smoking considered one of the three leading risk factors for global disease burden [2]. Smoking in adolescence is a health problem affecting one of the active age group. The average age of initiation was 15.7 years in USA [3] and the overall prevalence of smoking initiation among students was $11.9 \%$ [4]. Furthermore, approximately 1 out of 5 adolescents in Madagascar currently smoke cigarette [5]. A cross-sectional survey conducted in an Asian nation (Malaysia) revealed that 9\% of adolescents participated had ever tried smoking and more than half $62 \%$ of the current smokers had started smoking at or below the age of 11 years [6]. The prevalence of cigarette smoking was $10.2 \%$ in adolescents aged from 14 to 20 years in Iran [7]. Whereas, it was estimated to be $16.1 \%$ among Moroccan schoolboys [8].

It is observed that smoking prevalence in adolescence was increasing with age, for participants whose mean age was 12.8 years in Sweden, the baseline prevalence of smoking was $3.3 \%$, increasing to $25.1 \%$ at follow-up five years later [9]. Moreover, the percentage of Korean teenagers who ever

Published on June 13, 2020.

Ahmad Y. Alzahrani, Ministry of Health, Saudi Arabia.

(corresponding e-mail: ahmad96@hotmail.com) smoke in their lifetime increased with age; $12.8 \%, 24.7 \%$, and $31.4 \%$ of students aged $12-13$ years, $14-15$ years, and 16-18 years, respectively [10]. By consensus, a survey of 185.625 students aged 10-18 in Indonesia showed that older adolescents have higher opportunities to initiate tobacco smoking as compared to younger adolescents [11].

For this narrative review, we consulted PubMed database in July 2019, the search terms included "factors," "influencing," "risk," "promoting," and "smoking," "tobacco," "cigarette smoking," and "teenager," "adolescent," "underage". The search was covering literature published in the English language from 2008 to 9th July 2019 and limited to the free full text. Title and abstracts of the yielded article were reviewed to select the related results. Articles matching one of our subheadings namely; smoking in Saudi Arabia, factors promoting smoking among teenagers and strategies to minimize teenage smoking were retained in our review. References were excluded if they did not match our subtitles, and research on other smokeless tobacco or water pipe, shisha, hookah smoking were also eliminated.

\section{REVIEW}

\section{A. Smoking in Saudi Arabia}

In the Kingdome of Saudi Arabia, 9\% of ever smoker had started smoking before the age of 15 [12]. Furthermore, group of studies have shown the prevalence of current smoking in the Kingdome in different environments to be ranging from $17 \%$ to $25.3 \%$ in boys [13]. A lower prevalence was found in a study of 1186 students from intermediate and secondary schools in Jeddah city which was $9.2 \%$ [14].

A cross-sectional study conducted on 695 adolescents aged 11-16 years showed a prevalence of current smokers ranging from $35 \%$ at age 12 to $43.6 \%$ at age 15 [15]. Whereas another study in Riyadh showed a lower prevalence of $20 \%$ of students aged 14-19 whoever smoked [16], similarly other studies in Al Madinah showed a prevalence of current smokers of 20.8\% [17], and in Riyadh it was $19.5 \%$ [18]. Furthermore, those aged $17-19$ years tend to smoke cigarette more than younger students 14-17 years [16]. The current smoker percentage was found to be $15.1 \%$ among 3322 intermediate and secondary school who were surveyed in Madinah [19].

Almost ever-smokers in Tabuk area were males; $65.0 \%$ versus $23.1 \%$ of females as per a survey which was done on 1505 intermediate and high school students. More than 50\% of ever-smokers initiated the habit at age 10-13 years [20].

In Southern region of Saudi Arabia, a survey covering 72 
intermediate and secondary schools was carried out in Jazan with a study population of 3923 participants depicted that prevalence of students who ever smoked was $17.3 \%$, and the current smoking prevalence was $10.7 \%$. Also, the study revealed that the important risk factors for smoking initiation were academic performance (odds ratio OR: 5.32), having friends who used khat (OR: 3.23) and having friends who used tobacco (OR: 2.88) [21].

Regarding the number of cigarettes consumed by smokers, a study revealed that $74.1 \%$ of smokers in Saudi Arabia smoke cigarettes with an average of 15.1 cigarettes per day. Distribution of tobacco consumption by areas of the Kingdome showed the highest prevalence of current smoking in Tabuk, Al-Jawf, and Al Hudud Ash-Shamaliyah, at $18.5,18.3$, and $16.6 \%$, respectively [12].

\section{B. Factors Promoting Smoking Among Teenagers}

A variety of factors may affect the initiation of smoking among adolescent. These factors could be familial, personal, environmental, socioeconomic status and smoking advertisements.

Inside their families, parents are considered the higher examples for their offspring, when both parents are smokers the likelihood that their children will smoke rises dramatically [3], [11], [22]-[25]. The odds of using tobacco was found to be 3.4 and 1.14, respectively, for adolescents 15 to 24 years old living with mothers and fathers whose use tobacco, in comparison to youths staying with parents not taking tobacco [26]. Living with people other than children's parents was associated with cigarette smoking among highschool students [7] or living with siblings who smoke [3]. Surprisingly, one study conducted in Jamaica using a national survey data of 3365 students concluded that parental smoking status was not a predictor of the early age of cigarette smoking initiation among adolescents [27].

The environmental factors also play an important role in tobacco consumption among teenagers. Having nearby smokers increase the odds of smoking among adolescent by 5,8 and 12 in cases of 1,2 and 3 smokers respectively according to the analysis of a large survey of 198,714 schoolboys in Asia [28]. These results are aligned with other studies [17], [19] which revealed that schoolboys who have most or all of their friends smoke represent $48 \%$ of smokers and those living with neither parents are more prone to use tobacco $(\mathrm{OR}=3.3$; 95\% Confidence Interval $\mathrm{CI}=1.1-9.2)$.

Less than high school parental education was founded to be of significant effect on children starting smoking [3], [9], [10], also as compared to parents with a college/university degree, siblings of parents attended only high school have higher odds to initiate smoking at an earlier age [27]. Certain circumstances within the family were proven to enhance smoking in adolescents like poorer family mood [9], living in homes that allow smoking [3], [10] and not taking a family trip in the previous 12 months [10]. The effect of home smoking restriction on smoking initiation in adolescents was statistically significantly modified by paternal smoking [29].

Male gender is considered a risk factor [6], [8], [10], [11], [16], [23], [28] whereas in some studies being a female [9]. Moreover, low or average academic achievements [10], having troubles at school [30] and more than 10 days absence in school [22] considered risk factors as well. Lack of satisfaction about the adolescents themselves and poor self-esteem were related to their tobacco smoking habit [6], [9], whereas, some studies revealed having positive subjective health status could be also a risk factor [10]. Other predictors include; having smoking friend [3], [5]-[7], [30], less negative attitude to smoking [9], being thin and stressed [10], and a perception that boys who smoke are more attractive and look cool [25].

An association was established between positive attitudes toward smoking and the intention to smoke among high socioeconomic status HSES boys, whereas HSES girls had higher intentions to smoke if they perceived fewer disadvantages of smoking. The intention to smoke among low socioeconomic status LSES boys was predicted by perceived social norms; in LSES girls, the smoking behavior of people in their environment was most strongly related to their smoking intention [12].

Getting more pocket money [14], [15], [20] and living in more affluent family were linked to adolescent smoking in some study [28] whereas in another study in Asian country adolescents in the poorest quintile had more than twice the odds of smoking compared with adolescents from the richest quintile [11].

A longitudinal study conducted in Jordan concluded that waterpipe smoking led to the initiation of cigarette smoking among Jordanian adolescents and the effect was dosedependent [31].

Teenagers smoking can also be predicted by a commercial advertisement for smoking. Exposure to smoking industry promotion and retail marketing are associated with increased odds of initiation [4], [5]. Seeing smoking in movies is a predictor of smoking onset in various cultural contexts [32], [33] but more research is needed [33].

Finally, a systematic review for 30 studies with a total population of 26,709 participants aged 10 to 24 years was carried out in Nigeria and it summarizes main risk factors for tobacco smoking namely; peer influence, family conditions, psychosocial factors, and male gender [34].

\section{Strategies to Minimize Teenage Smoking}

Awareness about short term and long-term consequences of tobacco smoking may have preventive effects against initiating tobacco smoking among adolescent. A crosssectional study in eastern Saudi Arabia revealed that schoolboys who believed that smoking can adversely affect their oral health had a lower probability of smoking than those who were not aware of the negative consequences of tobacco use on oral tissues [35].

To emphasize the importance of awareness about smoking cigarettes among teenagers, a randomized controlled trial was conducted in Taif of Saudi Arabia were one arm of 698 randomly selected secondary school students underwent intensive smoking prevention program and a control arm of 683 students. The results showed that participants from the experimental group showed a significantly more negative attitude toward smoking than those from the control arm as well as more positive social norms towards nonsmoking, higher self-efficacy, more action planning to remain a nonsmoker, and lower intentions 
to start smoking [36].

Raising the allowed smoking age to 21 instead of 18 has been built since 2012 [37]. The Institute of Medicine IOM report in 2015 showed evidence that raising the minimum age to 21 would lead to a $12 \%$ reduction in smoking prevalence [37]. In 2005 Needham, Massachusetts USA, became the first town in the country to adopt such a law. The rate of smoking in high school was $12.9 \%$ before adopting 21 law which has declined to $6.7 \% 5$ years after implementing 21 law [38]. Number of US localities following this rule has increased from 8 in 2013 to be 125 in 2016. In 2015, the (Tobacco to 21 Act, S. 2100) was the first federal Tobacco 21 legislation [37]. Saudi Arabia has adopted regulations of framework convention on tobacco control-WHO FCTC regarding the allowed age of smoking to be 18 years [39] but more law enforcement is needed regarding minors smoking [40].

Excising taxes on cigarettes smoking was proved to be an effective intervention as described by a study in the United States US analyzing data to assess the relationship between excise taxes and prevalence of cigarette smoking in each state from 2001 to 2015 . They noticed a reduction of statelevel smoking prevalence ranged from 13.3 to $30.9 \%$ in 2001 ; to range of 9.1 to $26.1 \%$ in 2015 . The greatest impact on smoking prevalence was noticed in younger adults and weakest among low-income individuals. This effect further extended to those tried to quit smoking where with each $0.25 \$$ added to tax there is an estimated 0.67 increase in the percentage of active smokers reported trying to quit smoking [41].

\section{CONCLUSION}

In conclusion, adolescents are more prone to tobacco smoking as compared to other age groups and their uptake of this unhealthy habit can be predicted by some factors. Intervening in this age group is proven to be effective especially if tailored to target the more susceptible populations regarding gender, family situation, social factors, and geographic area. A national-wide smoking preventive program is recommended to tackle this public health concerns involving both improving awareness as well as restricting access to tobacco by minors.

\section{REFERENCES}

[1] WHO Report on the Global Tobacco Epidemic 2008. GenevaSwitzerland; 2008. https://www.who.int/tobacco/mpower/2008/en/.

[2] S. Lim, T. Vos, A. Flaxman, et al., "Comparative risk assessment of burden of disease and injury attributable to 67 risk factors and risk factor clusters in 21 regions, 1990-2010: a systematic analysis for the Global Burden of Disease Study 2010," Lancet, vol. 380(9859), pp. 2224-2260, December 2012.

[3] K. Goldade, K. Choi, D. Bernat, E. Klein, K. Okuyemi, J. Forster,"Multilevel predictors of smoking initiation among adolescents: findings from the Minnesota Adolescent Community Cohort (MACC) Study," Prev Med (Baltim), vol. 54(3-4), pp. 242246, March 2013.

[4] M. Johns, R. Sacks, M. Rane,S. Kansagra, "Exposure to tobacco retail outlets and smoking initiation among New York City adolescents," J Urban Heal Bull New York Acad Med, vol. 90(6), pp. 1091-1101, 2013.

[5] S. Veeranki, H. Mamudu, R. John, A. Ouma, "Prevalence and correlates of tobacco use among school-going adolescents in Madagascar," J Epidemiol Glob Health, vol. 5, pp. 239-247, January 2015 .
[6] M. Dahlui, N. Jahan, H. Majid, et al., "Risk and protective factors for cigarette use in young adolescents in a school setting: what could be done better?" PLoS One, vol. 10(6), pp. 1-12, June 2015.

[7] B. Moeini, J. Poorolajal, Z. Gharghani, "Prevalence of cigarette smoking and associated risk factors among adolescents in Hamadan city, west of Iran in 2010," J Res Health Sci.,vol 12(1), pp. 3137,February 2012.

[8] B. Bendaou, B. Zarrouq, K. El Kinany, et al., "Risk factors and prevalence of use of different tobacco products among school adolescents in the north central region of Morocco: A cross-sectional study," Pan Afr Med J, vol. 30, pp. 1-7, May 2018.

[9] J. Joffer, G. Burell, E. Bergström, H. Stenlund, L. Sjörs, L. Jerdén, "Predictors of smoking among Swedish adolescents," BMC Public Health, vol. 14(1269), pp. 1-9, 2014.

[10] E. So, J. Yeo," Factors associated with early smoking initiation among Korean adolescents," Asian Nurs Res (Korean Soc Nurs Sci), vol. 9(2), pp. 115-119, January 2015.

[11] N. Kusumawardani, I. Tarigan, A. Schlotheuber, "Socio-economic, demographic and geographic correlates of cigarette smoking among Indonesian adolescents: results from the 2013 Indonesian Basic Health Research (RISKESDAS) survey," Glob Health Action, vol. 11(1), pp. 1-9, April 2018.

[12] H. Cremers, L. Mercken, H. Vries, A. Oenema," A longitudinal study on determinants of the intention to start smoking among Nonsmoking boys and girls of high and low socioeconomic status," BMC Public Health, vol. 15(648), pp. 1-8, 2015.

[13] A. Al-Bedah1, N. Qureshi, "The global youth tobacco survey: 2001 - 2002 in Riyadh region, the Kingdom of Saudi Arabia," Subst Abuse Rehabil, vol. 2, pp. 197-204, November 2011.

[14] D. Alagili, H. Park, "The prevalence and determinants of tobacco use among adolescents in Saudi Arabia," J of School Health, vol. 82(3), pp. 131-138, 2012

[15] M. Mohammed, S. Eggers, F. Alotaiby, N. de Vries, H. de Vries, "Smoking uptake among Saudi adolescents: tobacco epidemic indicators and preventive actions needed," Glob Health Promot, vol. 25(2), pp. 6-15, July 2014.

[16] A. Al-Makadma, M. Moynihan, S. Dobson, E. Saewyc, "Tobacco use among adolescents in Riyadh Saudi Arabia," Int J Adolesc Med Health, vol. 27(3), pp. 357-360, 2015.

[17] A. Al-Zalabani, "Family context factors and the risk of smoking among male adolescents in Saudi Arabia," Asian Pacific J Cancer Prev, vol. 16(14), pp. 5847-5852, 2015.

[18] M. Al Ghobain, M. Al Moamary, S. Al Shehri, M. AL-Hajjaj, "Prevalence and characteristics of cigarette smoking among 16 to 18 years old boys and girls in Saudi Arabia,". Ann Thorac Med, vol. 6(3), pp. 237,July 2011.

[19] A. Al-Zalabani, K. Kasim, "Prevalence and predictors of adolescents' cigarette smoking in Madinah, Saudi Arabia: A schoolbased cross-sectional study," BMC Public Health, vol. 15(1), pp. 1-7, 2015 .

[20] A. Abdalla, A. Saeed, B. Abdulrahman, A. Al-Kaabba, H. Raat, "Correlates of ever-smoking habit among adolescents in Tabuk, Saudi Arabia," East Mediterr Heal J., vol. 15(4), pp. 983-992, 2009.

[21] A. Gaffar, R. Alsanosy, M. Mahfouz," Sociodemographic factor associated with tobacco smoking among intermediate and secondary school students in Jazan region of Saudi Arabia," Subst Abus, vol. 34(4), pp. 381-388, 2013.

[22] H. Roohafza, K. Heidari, T. Alinia, "Smoking motivators are different among cigarette and waterpipe smokers: the results of ITUPP," J Epidemiol Glob Health, vol. 5, pp. 249-258, January 2015.

[23] O. Odukoya, K. Odeyemi, A. Oyeyemi, R. Upadhyay, "Determinants of smoking initiation and susceptibility to future smoking among school-going adolescents in Lagos State, Nigeria," Asian Pac J Cancer Prev., vol. 14(3), pp. 1747-1753, 2013.

[24] A. Selya, L. Dierker, J. Rose, D. Hedeker, R. Mermelstein, "Risk factors for adolescent smoking: parental smoking and the mediating role of nicotine dependence," Drug Alcohol Depend., vol. 124(3), pp. 311-318, August 2012

[25] F. Bobo, P. Thanasekaran, A. Joice, B. Yadecha, A. Alebel, "Susceptibility to cigarette smoking and associated factors among high school students in western Ethiopia," BMC Res Notes., vol. 11(1), pp. 1-5, 2018.

[26] L. Ladusingh, P. Dhillon, P. Narzary,"Why do the youths in northeast India use tobacco?," J Environ Public Health, vol. 2017,pp. 1-7, May 2017.

[27] C. Agu, S. Weaver,W. Abe, et al.,"Are Adolescents likely to start smoking early if their parents are smokers? a study of Jamaican high school students," Asian Pac J Cancer Prev, vol. 19(S1), pp. 2531,2018 . 
[28] D. Kim, S. Kim, "Impact of nearby smoking on adolescent smoking behavior in Korea," Med (United States), vol. 97(45), pp. 1-7, 2018.

[29] D. Luh, H. Chen, A. Yen, et al., "Effect of self-reported home smoking restriction on smoking initiation among adolescents in Taiwan : a prospective cohort study," BMJ Open, vol.5, pp. 1-10, 2015.

[30] J. Tucker, M. Edelen, D. Kennedy, "Resisting smoking when a best friend smokes: do intrapersonal and contextual factors matter?," $J$ Res Adolsc, vol. 22(1), pp. 113-122, March 2012.

[31] R. Jaber, P. Madhivanan, E. Veledar, Y. Khader, F. Mzayek, W. Maziak, "Waterpipe a gateway to cigarette smoking initiation among adolescents in Irbid , Jordan: a longitudinal study," Int J Tuberc Lung Dis, vol. 19,pp. 481-487, November 2015.

[32]. E. Florek, K. Hunt, H. Sweeting, F. Mathis, "Smoking in movies and adolescent smoking initiation: longitudinal study in six european countries," Am J Prev Med, vol. 44(4), pp. 339-344, April 2014.

[33] M. Farrelly, K. Kamyab, J. Nonnemaker, E. Crankshaw, J. Allen, "Movie smoking and youth initiation: parsing smoking imagery and other adult content," PLoS One, vol. 7(12), pp. 26-28, December 2012.

[34] B. Oyewole, V. Animasahun, H. Chapman, "Tobacco use in nigerian youth: a systematic review," PLoS One, vol. 13(5), pp. 1-13, May 2018.

[35] M. Nazir, K. Almas, "Awareness about the effects of tobacco consumption on oral health and the possibility of smoking behavior among male Saudi schoolchildren," Eur J Dent, vol. 11(1), pp. 2935, January 2017.

[36] M. Mohammed, S. Eggers, F. Alotaiby, N. de Vries, H. de Vries,"Effects of a randomized controlled trial to assess the sixmonths effects of a school based smoking prevention program in Saudi Arabia," Prev Med (Baltim), vol. 90, pp. 100-106, 2016.

[37] S. Morain, J. Winickoff, M. Mello, "Have Tobacco 21 Laws come of age?," N Engl J Med, vol. 374(17), pp. 1601-1604, April 2016.

[38] J. Winickoff, M. Gottlieb, M. Mello, "Tobacco 21 - an idea whose time has come," N Engl J Med, vol. 370(4), pp. 2011-2016, January 2014.

[39] M. Al-Munif, Report on Tobacco Control Program of Ministry Of Health in Saudi Arabia. Riyadh-Saudi Arabia; 2009. http://www.satcp.com/newsite/user/pdf/REPORT_ON_TCP.pdf.

[40] M. lakeh, C. ElBcheraoui, M. Tuffaha, et al., "Tobacco consumption in the Kingdom of Saudi Arabia, 2013: findings from a national survey," BMC Public Health, vol 15(611), 2015.

[41] M. Sharbaugh, A. Althouse, F. Thoma, J. Lee, V. Figueredo, S. Mulukutla, "Impact of cigarette taxes on smoking prevalence from 2001-2015: A report using the Behavioral and Risk Factor Surveillance Survey (BRFSS)," PLoS One, vol. 13(9), pp. 1-10, September 2018. 